\title{
Numerical and Experimental Investigations on the Effects of Variable Cavity Pressure on the Formability of GLARE Using Hydromechanical Deep Drawing
}

Muhammad Nazim Tabasum

Beihang University https://orcid.org/0000-0001-8329-622X

Lihui Lang ( $\sim$ lang@buaa.edu.cn )

Beihang University

Hasnain Ali Mirza

Beihang University

Zhang Meng

Beihang University

Hamza Blala

Beihang University

\section{Research Article}

Keywords: Variable cavity pressure (VCP), GLARE, Fiber Metal Laminates (FMLs), Hydroforming, hydromechanical deep drawing (HMDD)

Posted Date: November 29th, 2021

DOI: https://doi.org/10.21203/rs.3.rs-933342/v1

License: (c) (i) This work is licensed under a Creative Commons Attribution 4.0 International License. Read Full License

Version of Record: A version of this preprint was published at The International Journal of Advanced Manufacturing Technology on January 18th, 2022. See the published version at https://doi.org/10.1007/s00170-021-08518-w. 


\title{
Numerical and experimental investigations on the effects of variable cavity pressure on the Formability of GLARE using Hydromechanical Deep Drawing
}

\author{
Muhammad Nazim Tabasum. Lihui Lang. Hasnain Ali Mirza. Zhang Meng. Hamza Blala. \\ Department of Mechanical engineering and Automation, Beihang University, Haidian District, Beijing 100191, \\ People's Republic of China
}

\section{Corresponding Author}

Lihui Lang

lang@buaa.edu.cn

\begin{abstract}
Excellent physical and mechanical properties of fiber metal laminates (FMLs) have made them a very popular and most suitable material to make high strength and lightweight products in different industries for example automobile, military, and aerospace. Glass fiber aluminum reinforced epoxy (GLARE) is one of the most used fiber metal laminate among the family of fiber metal laminates, but there are some challenges in its formability. Our study mainly focuses on the formability of the GLARE cup parts by using hydromechanical deep drawing. Forming depth with good quality (without any wrinkling, delamination, or fracture), failure mode analysis and wall thinning rate (\%) distribution of the parts are the main criteria in the formability. The influence of variable cavity pressure (VCP) with respect to punch strokes had been investigated by using numerical simulations and experiments. Results showed that the variable cavity pressure in case of increasing or decreasing the cavity pressure had very much effect on the formability. Stepwise increasing the VCP with respect to punch strokes resulted in a maximum forming depth of $29.00 \mathrm{~mm}$ as well as good quality whereas in the case of stepwise decreasing the variable cavity pressure, results were not encouraging. Commercially available code ABAQUS explicit was used for finite element analysis simulation which had shown close agreement with the experimental results.
\end{abstract}

Keywords: Variable cavity pressure (VCP), GLARE, Fiber Metal Laminates (FMLs), Hydroforming, hydromechanical deep drawing (HMDD)

\section{Introduction}

Increasing efficiency by reducing vehicle weight while maintaining high safety is one of the primary aims of numerous industries such as aerospace and automobile in the modern era. Hence they are very eager in search of such materials which have better mechanical properties like high strength-to-weight ratio, fatigue, impact, flame, and corrosion resistance. Different materials like aluminum alloys and steel had played a very important role and were employed in automobile and aircraft industries for decades for this reason. Despite having good mechanical and physical properties these materials have some drawbacks for example high weight, low impact, fatigue, and flame resistance as compared to composite materials due to which they are not suitable to fulfill other essential requirements [1][2]. Hence, to achieve these goals and to overcome the drawbacks of monolithic alloys, fiber metal laminates (FMLs) are one of the better choices. They are hybrid composite materials composed of layers of thin metal and fiber-reinforced adhesives 
alternately bonded together. Figure 1 (a) shows the representation of fiber metal laminates (FMLs). They combine fiber-reinforced polymer properties (stiffness and strength) with the advantages of metal alloys (toughness and durability) [3].

Their outstanding mechanical features have made them a strong contender for the fuselage and lower wing skin materials in the next generation of big aircraft [4]. For example, GLARE (glass fiber aluminum reinforced epoxy) is a promising candidate material for fuselage skin structures of the new generation of high-capacity aircraft due to its outstanding fatigue resistance, high specific-static properties, excellent impact resistance, good residual and bluntnotch strength, flame resistance, corrosion properties and ease of manufacture and repair [5].

The failure strains of metals or alloys are extremely high, ranging from 10 to $50 \%$, whereas the formability of composite fibers is extremely limited. Carbon, aramid, and glass fibers have failure strains of about $1 \%, 2-2.5 \%$, and $4-5 \%$, respectively. The matrix or resin failure strain in a prepreg is also limited, particularly for thermoset polymers [6]. Over time the development of advanced manufacturing technologies, the forming of different new materials with a high degree of flexibility has become very important.

Hydroforming is one of the most essential and common forming processes that was developed around since before World War II, but it had only been used in a few industries. It has gained a lot of attention in several industries, particularly in the automobile industry since the 1990s [7]. Sheet metal forming techniques with the help of fluid pressure have become very useful and their importance greatly increased because of some advantages over conventional sheet metal forming technologies. Different kinds of sheet materials can be formed by using sheet hydroforming technology, including steels, alloys of aluminum, magnesium, titanium, copper, and composite sheets. Hydromechanical deep drawing (HMDD) is one of the important process assisted by fluid pressure that combines both the deep drawing and hydroforming technology in which punch strokes forces the laminate inside the die while pressurized fluid pushes the laminate tightly onto the surface of the punch. In this process limit drawing ratio is about 2.8 which is much higher than the traditional deep drawing which is 2.2. It also has too many applications in the automobile and aircraft industries [8] [9].

Pressure in hydroforming is one of the most effective parameters that has a huge effect on the formability of forming parts, hence needs to be investigated thoroughly. Different researchers have made investigations about the effect of pressure in their studies, for example, Gorji et.al in their study about the forming of conical-cylindrical cups investigated the impact of pressure path on defects, thickness distribution, and drawing ratio. They came to the conclusion that at low pressures, rupture happens on the sheet's contact area with the punch edge. The cup was made at larger pressures; however, the wall thickness distribution was dependent on the pressure path. Also, cups with a high deep drawing ratio were accomplished by using the desired pressure path [10]. Wang et.al in their research calculated the process window diagram (PWD) in the hydrodynamic deep drawing (HDD) process of a composite conical box with double concave cavities through theoretical analysis, numerical simulation, and process experimentation. The effect of cavity pressure loading locus on forged component forming quality and aluminum alloy deformation behavior was investigated and found that the initial pressure, full pressure, and loading locus are the essential aspects that are directly related to forming quality and dimensional accuracy. For the thickness 
homogeneity of the double concave attributes in the conical section with composite features, a reasonable beginning pressure value is critical while the full pressure's magnitude is critical for enhancing the conical feature's quality [11]. Khademi et.al studied the wrinkling wave in the formed conical cups of copper and St13 both numerically and experimentally in the hydrodynamic deep drawing process with the help of radial pressure and inward flowing liquid. They also looked into the impacts of these pressures on the created components and found that by managing the maximum wrinkling height parameter as a result of pressure change, they were able to form a piece that was free of wrinkling and rupture [12]. Li et.al investigated the effect of pre-forming depth and loading loci of cavity pressure on the work piece's dimensional accuracy and thickness variation, and a well-formed conical part with desirable surface quality and high dimensional accuracy was obtained by controlling the full cavity pressure in the pre-forming and final forming stages in the ranges of 10-15 MPa and 8-15 MPa, respectively [13]. Hydrostatic pressure's impact on the wrinkling phenomena in the HMDD process of the hemispherical cup with Al 6111-T4 material was studied and they found that sheet stretched in the flange area due to hydrostatic pressure, while the external support created compressive stress which decreased the production of wrinkles owing to tensile friction and slowed the occurrence of tension instability [14]. Kamran et.al developed a theoretical model relying on the BBC2008 yield criterion with 8 and 16 parameters $(8 \mathrm{p}$ and $16 \mathrm{p})$ and verified experimentally as well to identify the critical pressure in the HMDD process [15]. Zafar et al. studied the simultaneous forming of three-layer metallic blanks by HMDD and proved that forming depth can be improved by using cavity pressure in a controlled way as well as their thinning and wrinkling are very dependent on Blank holder force (BHF) and cavity pressure. They also discovered that applying cavity pressure within specified limits improved the quality of three-layer produced parts and led to higher depths as compared to the method when no cavity pressure was used [16] [17]. Zhang et.al found that cavity pressure less than the optimal value resulted in wrinkling and more than the optimal value in fracture [18]. Zhang et al. also developed an orthogonal test approach for evaluating forming conditions in the simultaneous formation of three layers of metallic blanks and optimized the parameters that influence them, one of which was the pre-bulging pressure [19]. Blala et.al found that applying cavity pressure within the specified range had a good impact on the molded cup's quality and resulted in a greater depth [20]. Lei li et.al found that increment of cavity pressure reduced the delamination [21]. Also, [22] studied the forming of pure copper cylindrical cups to find the effects of two pressure paths, liner pressure path, and step pressure path, on the thickness distribution by using finite element (FE) simulations and experiments with the help of radial pressure through hydrodynamic deep drawing and found that by choosing the step pressure path, the quality of the formed cup improved as well as they obtained more uniformity of thickness distribution.

Lihui et.al studied the impact of important process factors in HMDD on the forming process and found that pressure in the die and shape of the blank had a significant impact and the part can only be successfully produced by combining the optimal shape of the blank and pressure [23]. Also, Lihui et. al found that the thickness distribution was greatly affected by variations in liquid pressure. The wall thickness increased when the die cavity's liquid pressure was low [24]. Deep et.al presented a mathematical approach for predicting a safe zone for cavity pressure and blank holder pressure in the HMDD to avoid compressive and tensile instabilities [25]. Yaghoubi et.al in their study found that the quality and consistency of the final double-layer product were improved by applying an optimized value of fluid pressure of $15 \mathrm{MPa}$ to the underside of the workpiece. The bending and tensile stresses at the punch tip were more 
consistently distributed in the presence of this amount of pressure, and the level of thinning was significantly reduced when compared to the usual deep drawing technique [26]. Furthermore, Jalil et al. [27] provided a theoretical model for calculating the critical rupture pressure in the manufacturing of double-layered conical pieces using a hydrodynamic deep drawing process with radial pressure as a helper. Both the bottom surface and the peripheral edge of sheets were subjected to hydrodynamic pressure during this process. The results revealed that increasing the coefficient of friction at the flange area lowers the critical pressure and resulted in a premature rupture. During the forming process, changing the coefficient of friction from 0.05 to 0.15 reduced the critical pressure from 135-300 MPa to 55-80 MPa. Aside from being higher, drawing ratios resulted in a narrower critical pressure range. Besides higher, drawing ratios resulted in a limited range of critical pressure. For drawing ratios greater than 4 , precise pressure loading determination and control were necessary to create non-defective parts.

From the literature review, it becomes clear that cavity pressure has a huge effect on the formability as well as failure modes of forming parts. Also literature available related to pressure is limited to constant values while our study is about the effect of VCP w.r.t punch strokes in the forming of glass fiber reinforced aluminum laminates (GLARE) cup parts by using HMDD.

\section{Materials preparation and experimentation}

In this study GLARE cup parts had been formed by using HMDD for which semi-cured 2/1 GLARE laminates were used. The material used was metallic sheets of aluminum 2024-T3 as the skin layers and woven glass fiber prepreg as the core layer. Both sheets having a thickness of $0.5 \mathrm{~mm}$ and $0.2 \mathrm{~mm}$ respectively were cut into circular shapes with a diameter of $140 \mathrm{~mm}$ by using a wire cut machine. Before making the laminates surface treatment of $\mathrm{Al}$ sheets by chemical anodizing had been done to improve the interface adhesion performance between outer aluminum layers and middle glass fiber. Figure 1 (b) and (c) show the wire cutting and alkaline washing of metal layers respectively. At room temperature, the tensile properties of aluminum were evaluated using dog-bone-shaped specimens cut in the rolling direction, in accordance with ASTM E8 standards. Table 1 shows the mechanical characteristics of aluminum 2024-T3 and prepreg. The unidirectional tensile test was carried out according to the standard requirements ASTM D3039 and ASTM-E8 for semi-cured glass prepreg and aluminum respectively. Stress-strain curves for both are given in figure 3 as well. Tensile properties were tested on CTM-100G universal testing machine as well as with the usage of the extensometer where the load was applied at the rate of $2 \mathrm{~mm} / \mathrm{min}$. Experiments were performed at room temperature on a 50-ton hydroforming machine which is shown in figure 2 . This machine was managed by a hydraulic feed controller which was linked to computer software that measured various forming process parameters such as blank holder force, cavity pressure, feed rate, and deep drawing distance. A fixed die-holder gap of $1.1 \mathrm{~mm}, 12 \mathrm{KN}$ blank holder force was applied whereas cavity pressure was changed according to requirements in each experiment. Equipment used consisted of punch, blank holder, and die having diameters of $79 \mathrm{~mm}, 80 \mathrm{~mm}$, and $83 \mathrm{~mm}$ respectively whereas, surface roughness between punch and die was $0.2 \mu \mathrm{m}$. 


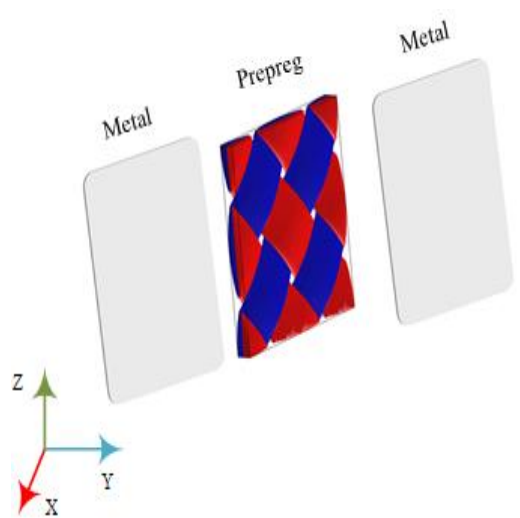

(a)

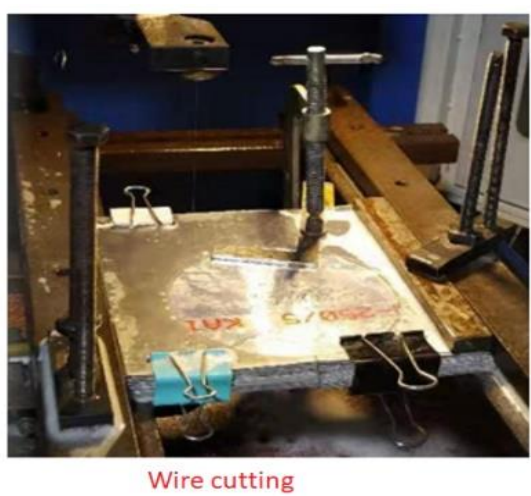

(b)

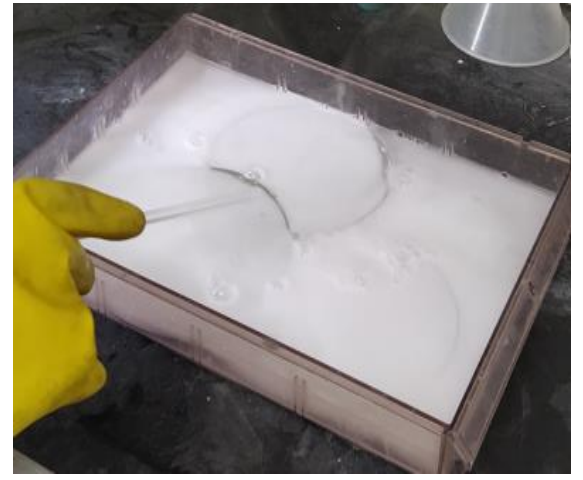

(c)

Figure 1: (a) Representation of fiber metal laminates (FMLs) (b) cutting of metal layers by wire cut machine (c) Alkaline washing of metal layers

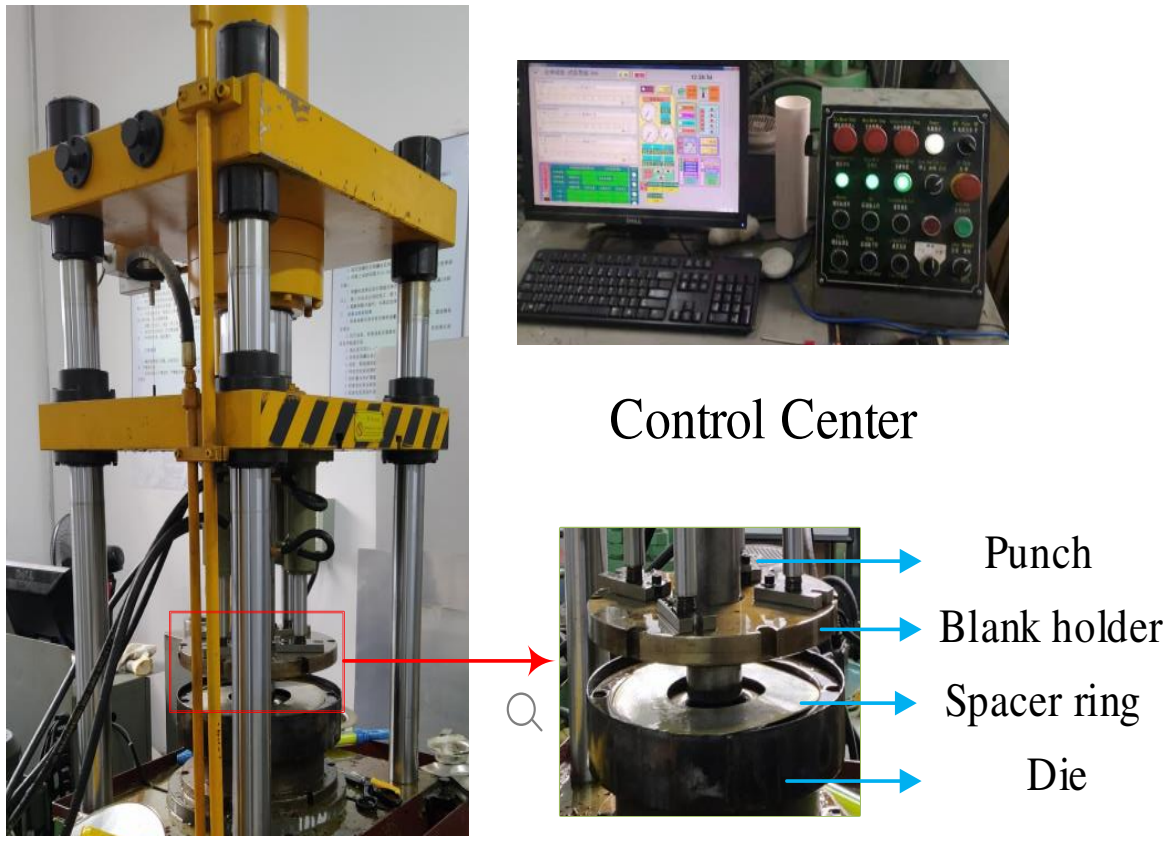

Figure 2: Hydroforming machine 
Table 1: Mechanical Properties of Al 2024-T3 and prepreg

\begin{tabular}{|l|l|l|l|l|l|l|}
\hline Material & $\begin{array}{l}\text { Ultimate tensile } \\
\text { strength (MPa) }\end{array}$ & $\begin{array}{l}\text { Yield } \\
\text { strength at } \\
0.2 \%(\mathrm{MPa})\end{array}$ & $\begin{array}{l}\text { Modulus of } \\
\text { elasticity } \\
(\mathrm{GPa})\end{array}$ & $\begin{array}{l}\text { Strain } \\
\text { hardening } \\
\text { exponent }\end{array}$ & Strain ratios & $\begin{array}{l}\text { Poisson's } \\
\text { ratio } v\end{array}$ \\
\hline 2024-T3 & 502 & 278 & 65.0 & 0.28 & 0.82 & \\
\hline prepreg & $\mathrm{E} 1(\mathrm{GPa})$ & $\begin{array}{l}\mathrm{E} 2(\mathrm{GPa}) \\
23\end{array}$ & $\begin{array}{l}\mathrm{G} 12(\mathrm{GPa}) \\
5.4\end{array}$ & $\begin{array}{l}\mathrm{Xt} \\
1213\end{array}$ & $\begin{array}{l}\text { Yt } \\
1213\end{array}$ & 0.23 \\
\hline
\end{tabular}

E1 and E2: modulus of elasticity in the warp and weft direction respectively, G12: modulus of shear in-plane, Xt and Yt: tensile strength in the warp and weft direction respectively, $v$ : Poisson's ratio

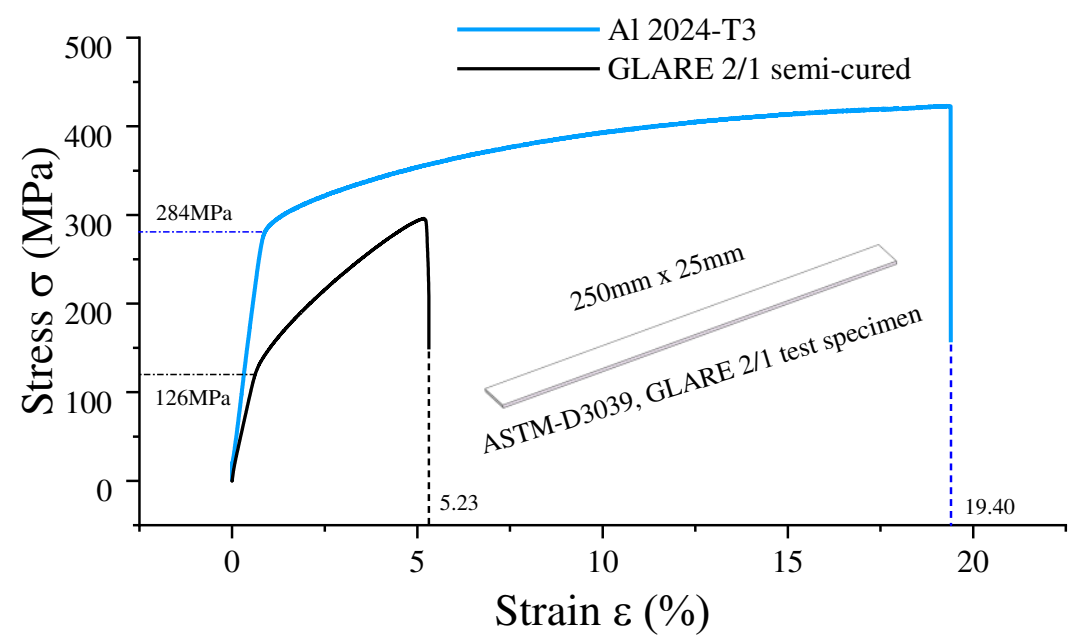

Figure 3: Stress-strain curve for Al2024-T3 and semi-cured 2/1 GLARE

\section{Numerical Simulation}

Non-conventional blank holding techniques were studied by Wifi and Mosallam for the forming of $1 \mathrm{~mm}$ thick Al5182 blank and they found that a gap less than the total thickness of the blank successfully resulted in the elimination of wrinkles [28]. Lei li et.al found that a blank holder gap greater than laminate thickness results in wrinkling and found an optimized value of $1.15 \mathrm{~mm}$ whereas the total thickness of laminate was $1.2 \mathrm{~mm}$ [21]. Also, Blala et. al in his study of process parameters such as blank holder gap, cavity pressure, and blank holder force on the final quality of hemispherical cup made of $1.2 \mathrm{~mm}$ thickness $2 / 1$ glare laminate achieved by using mechanical hydroforming and got good results in making the significant depth of $26 \mathrm{~mm}$ with no wrinkling while having a suitable blank holder gap of $1.1 \mathrm{~mm}$ which was less than the total thickness of [29]

Hence, in our study $1.1 \mathrm{~mm}$ fix BHG was used. Finite element analysis software ABAQUS explicit was used to make the numerical simulation. Cup parts of 2/1 GLARE laminate had been made by using HMDD. Figure 4 shows the whole simulation setup model which consists of a punch, a blank holder, a die as well as two layers of aluminum, and one layer of woven prepreg glass fiber. Punch and blank holder were free to move in Z-axis. 
Elastic and plastic properties of aluminum coupled with lamina as well as expansion factors were imported into the simulation setup in the material property module. To minimize the computation time, the punch, blank holder, and die were considered as rigid whereas aluminum and woven glass prepreg layers as deformable parts. Four coefficients of friction were used between punch-upper aluminum sheet, blank holder-upper aluminum sheet, die-lower aluminum sheet, and aluminum sheets-woven prepreg glass fiber sheet which were $0.15,0.1,0.05$, and 0.3 respectively. Two different loads were applied, one was a uniform blank holder force of $12 \mathrm{KN}$ and 2nd was VCP to get the required properties in the HMDD of the cup part. Fix blank holder gap of $1.1 \mathrm{~mm}$ as explained above was used, also an amplitude tool w.r.t step time was applied in the software.

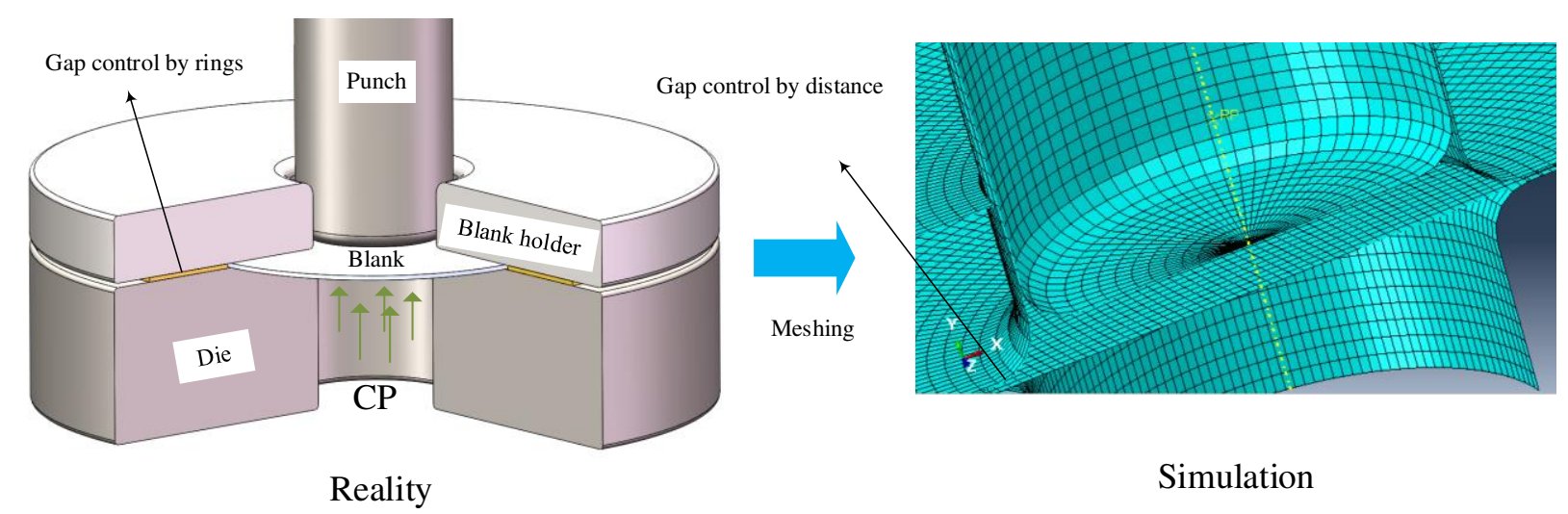

Figure 4: Model used for the numerical simulations

\section{Results and Discussion}

In this investigation, different parameters were set including blank holder force $12 \mathrm{KN}$ and blank holder gap $1.1 \mathrm{~mm}$ were fixed while cavity pressure was changed from 2 to $10 \mathrm{MPa}$ to obtain the results as given in tables $2 \mathrm{~A}$ and $2 \mathrm{~B}$. Results showed that lower or stepwise decreasing the cavity pressure resulted in sidewall wrinkling whereas high cavity pressure fractured the part early (Figure 9) and between these, there was an optimal value at which good quality part with maximum depth formed. Also, a maximum forming depth of $29.00 \mathrm{~mm}$ was obtained while increasing the cavity pressure stepwise w.r.t punch strokes which is termed as stepwise increasing VCP here. 
Table 2A: Cavity pressure using only 1 step

\begin{tabular}{|c|c|l|l|l|c|}
\hline Specimen \# & $\begin{array}{l}\text { Influencing } \\
\text { factor(s) }\end{array}$ & \multicolumn{4}{|c|}{ Evaluation } \\
\cline { 2 - 6 } & $\begin{array}{c}\text { CP [MPa] } \\
\text { (Only 1 step) }\end{array}$ & \multicolumn{3}{|c|}{$\begin{array}{c}\text { Maximum wall thinning rate (\%) } \\
\text { (Simulation) }\end{array}$} & $\begin{array}{l}\text { Depth achieved } \\
\text { (without any wrinkles, } \\
\text { delamination and fracture) } \\
\text { [mm] }\end{array}$ \\
\cline { 2 - 6 } & & Al upper & $\begin{array}{l}\text { Middle } \\
\text { layer }\end{array}$ & Al lower & 19.00 \\
\hline $\mathbf{A - 1}$ & 2 & 10.85 & 4.85 & 12.75 & 22.50 \\
\hline $\mathbf{A - 2}$ & 4 & 11.91 & 5.30 & 13.70 & 23.00 \\
\hline $\mathbf{A - 3}$ & 5 & 12.55 & 5.35 & 13.80 & 25.00 \\
\hline $\mathbf{A - 4}$ & 6 & 13.56 & 5.50 & 14.75 & 26.50 \\
\hline $\mathbf{A - 5}$ & 8 & 13.21 & 5.60 & 14.53 & 25.00 \\
\hline $\mathbf{A - 6}$ & 10 & 13.05 & 5.40 & 14.25 & \\
\hline
\end{tabular}

Table 2B: Cavity pressure using VCP in 3 steps

\begin{tabular}{|c|c|c|c|c|c|c|c|}
\hline \multirow{3}{*}{$\begin{array}{l}\text { Specimen } \\
\#\end{array}$} & \multirow{2}{*}{\multicolumn{3}{|c|}{$\begin{array}{c}\text { Influencing factor(s) } \\
\text { VCP (3 Steps) } \\
{[\mathrm{MPa}]}\end{array}$}} & \multicolumn{4}{|c|}{ Evaluation } \\
\hline & & & & \multicolumn{3}{|c|}{$\begin{array}{l}\text { Maximum wall thinning rate }(\%) \\
\text { (Simulation) }\end{array}$} & \multirow{2}{*}{$\begin{array}{l}\text { Depth achieved } \\
\text { (without any wrinkles, } \\
\text { delamination and fracture) } \\
\quad[\mathbf{m m}]\end{array}$} \\
\hline & Step 1 & $\begin{array}{l}\text { Step } \\
2\end{array}$ & Step 3 & Al upper & $\begin{array}{l}\text { Middle } \\
\text { layer }\end{array}$ & Al lower & \\
\hline B1 & 2 & 5 & 8 & 14.15 & 5.66 & 14.96 & 29.00 \\
\hline B2 & 8 & 5 & 2 & 14.33 & 5.85 & 15.55 & 23.00 \\
\hline B3 & 5 & 8 & 10 & 13.17 & 5.55 & 14.48 & 27.00 \\
\hline
\end{tabular}

Table 3: Stepwise increasing the VCP w.r.t punch strokes (PS)

\begin{tabular}{|c|c|c|}
\hline $\begin{array}{c}\text { Punch strokes } \\
(\text { PS \#) }\end{array}$ & $\begin{array}{c}\text { Punch travelling distance } \\
{[\mathbf{m m}]}\end{array}$ & $\begin{array}{c}\text { Stepwise increasing the VCP } \\
{[\mathrm{MPa}]}\end{array}$ \\
\hline PS 1 & $0-13$ & 2 \\
\hline PS 2 & $13-21$ & 8 \\
\hline PS 3 & $21-29$ & 5 \\
\hline
\end{tabular}




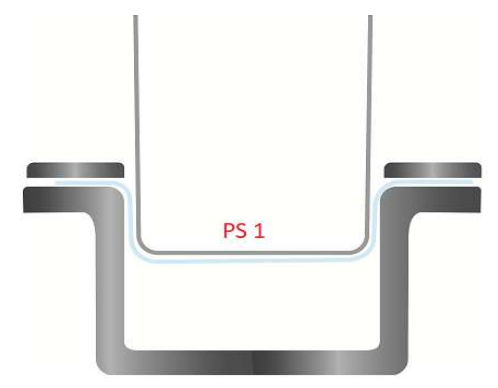

(a)

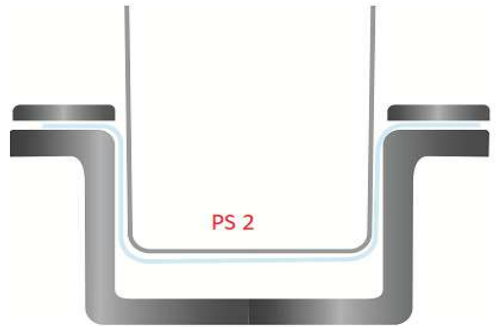

(b)

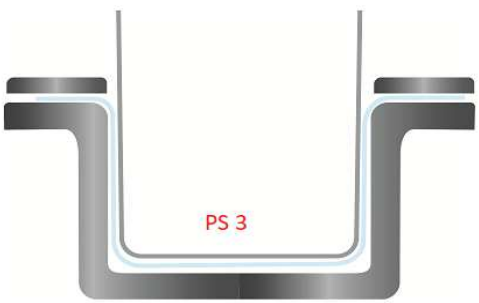

(c)

Figure 5: Representation of punch strokes (a) Punch stroke 1 (b) Punch stroke 2 (c) Punch stroke 3

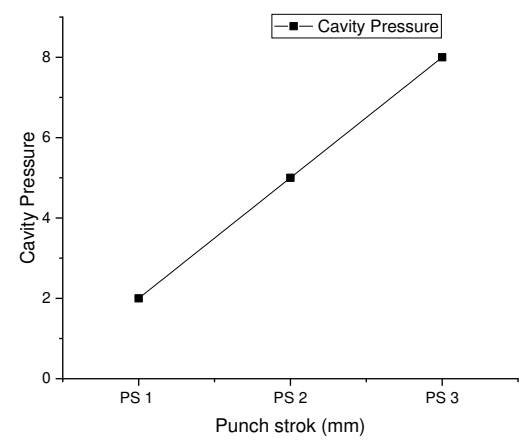

Figure 6: Graphical representation of increasing VCP with PS1, PS2 and PS3

\subsection{Effect of VCP on forming limit depth}

Table $2 \mathrm{~A}$ shows that the cavity pressure was changed from 2 to $10 \mathrm{MPa}$ in only one step whereas in this study a fixed blank holder gap and blank holder force of $1.1 \mathrm{~mm}$ and $12 \mathrm{KN}$ were used respectively. At these conditions, $8 \mathrm{MPa}$ cavity pressure was the optimal value at which maximum forming depth, as well as good quality part (without any wrinkling, delamination, or any kind of fracture) was obtained. Based on these values further stepwise increasing and decreasing of the cavity pressure or VCP was studied.

As given in Table 2B that instead of using constant cavity pressure when we used three different cavity pressures with respect to punch stroke, results were different. Punch stroke, which was the total distance traveled in the forming of the part i.e. $29 \mathrm{~mm}$, and was divided into three strokes. Here from 0-13, 13-21,21-29 mm were the first, second, and third punch strokes respectively. Also, pressure given in step 1, step 2, step 3 was applied to punch stroke 1, punch stroke 2, and punch stroke 3 respectively. Figures 5, 6, and 7 show the representation of punch strokes, graphical representation of increasing VCP with PS1, PS2, and PS3, and parts made at stepwise increasing VCP respectively. Here when we increased the pressure stepwise in three different steps from 2 to $8 \mathrm{MPa}$ then maximum depth 29.00 $\mathrm{mm}$ as well as good quality of the part obtained. Actually whatever the blank holder gap, blank holder force, or cavity pressure was used, forming depth will be more than 13mm [30]. Hence after this depth forming becomes more critical and to be investigated thoroughly, for this reason, punch stroke was divided into three strokes in which second and third punch strokes start after $13 \mathrm{~mm}$ and $21 \mathrm{~mm}$ respectively. In the second stroke in specimen B1 cavity pressure, 5 
MPa was applied till $21 \mathrm{~mm}$ depth and after it, the most critical forming depth area starts in which optimized value of $8 \mathrm{MPa}$ (got from table $2 \mathrm{~A}$ ) was applied due to which results were very encouraging as compared to pressure applied in one step. In this most critical forming region that starts after $13 \mathrm{~mm}$, tensile and bending stresses would be gradually raised as the punch moved, necessitating a rise in cavity pressure in the same way, to push and hold the laminate around the punch by providing sufficient supportive force.

And when we decreased the pressure as given in table 2B for specimen $\mathrm{B} 2$ from 8 to $2 \mathrm{MPa}$, then the lower depth of the part obtained as compared with applying both the constant cavity pressures and at stepwise increasing because at lower cavity pressure flowing of material inside the die becomes easy. In this case, 2 MPa cavity pressure was applied in the third stroke due to which wrinkling of middle layer started at depth just after $23 \mathrm{~mm}$ because of insufficient supportive force due to lower cavity pressure as shown in figure 8 and after it was going to be increased.
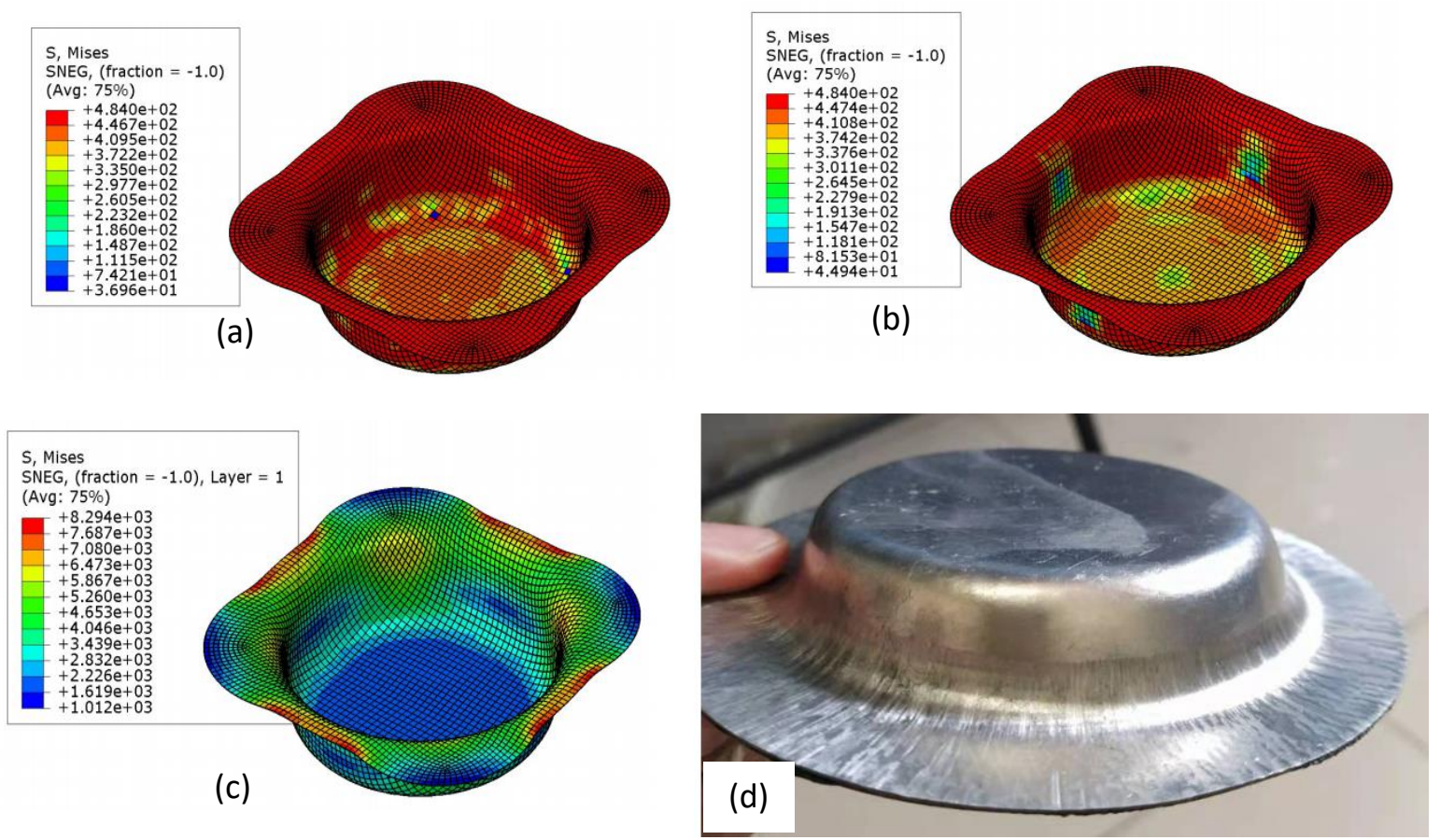

Figure 7: Stepwise increasing VCP (a) Al upper layer (b) Al lower layer (c) Middle layer (glass prepreg) (d) GLARE cup part made at stepwise increasing VCP (Experiment)
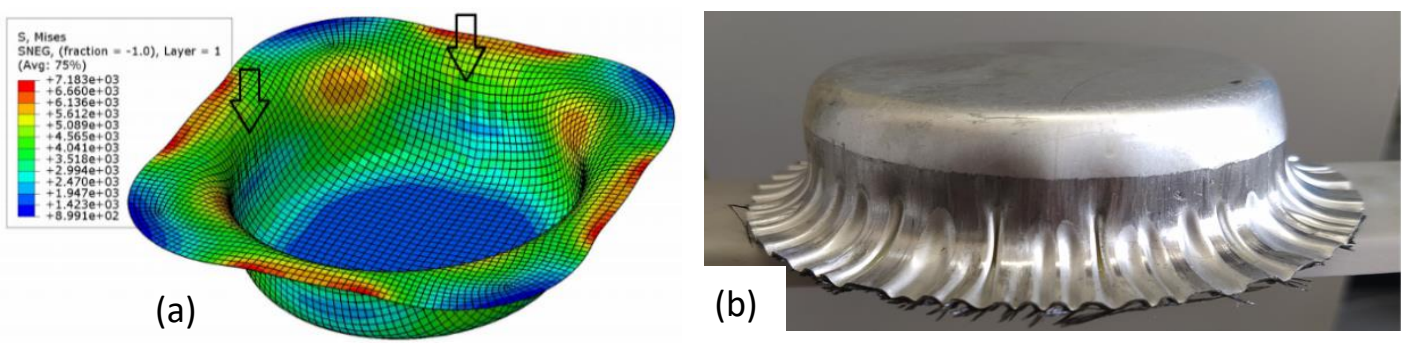

Figure 8: Sidewall wrinkling started after $23 \mathrm{~mm}$ while decreasing the VCP (a) simulation (b) experiment 


\subsection{Failure mode analysis}

In the formability of fiber metal laminates, there are mainly three types of failures that occur which are wrinkling, delamination and fracture, and part without any failure is considered as good quality part. Also, middle layer is the most critical as well as an affected part in the FMLs which ultimately affects the overall results. VCP has a very much effect on these failures. Stepwise decreasing the VCP resulted in sidewall wrinkling failure of the middle layer after just $23 \mathrm{~mm}$ of depth as shown in figure 8 because of insufficient supporting force to mend the wrinkles at the last step when stresses were at peak whereas high pressure resulted in early fracture failure at the punch corner radius which is the most thinning region of three layers as well. Cavity pressure higher than the optimal value either in one step or by variably increasing exerted excessive normal forces against the walls of the part under thinning throughout the formation phase as well as the large radial tensile strain along the part's curvature. Maximum stress was generated at the cup part's curvature or punch radius region, which was also the thinnest section, resulting in excessive in-plane stress, causing the component to fracture at the same spot as shown in figure

9. Actually first of all, prepreg fractured because of its limited formability as compared to metal and right after it failure occurred. VCP increased to $8 \mathrm{MPa}$ resulted in good quality part which was the optimal value in this study.

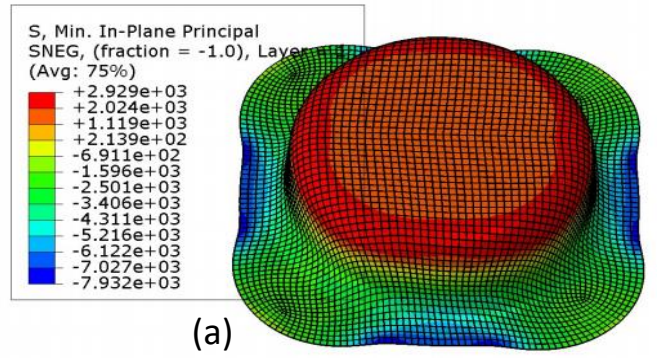

(a)

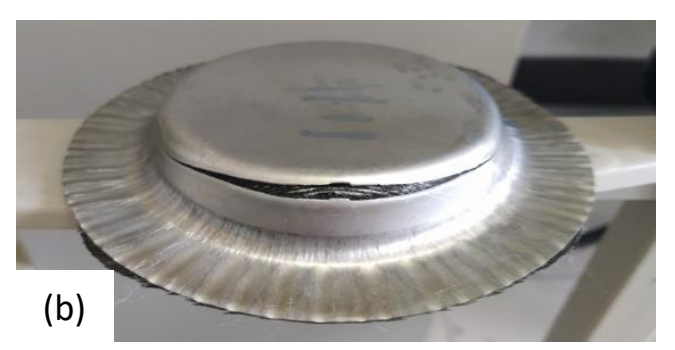

Figure 9: Early fracture at high pressure of stepwise increasing the VCP upto $10 \mathrm{MPa}$ (a) simulation (b) experiment

\subsection{Effect of VCP on wall thinning rate distribution}

As given above that parts had been made at both stepwise increasing and decreasing the pressure and then part made at stepwise increasing the VCP which is also our optimized part. Thickness at different points was measured by using simulations. Lower pressure resulted in higher thinning of the parts as can be observed in table $2 \mathrm{~A}$. Also by increasing the VCP stepwise resulted in lower thinning of the middle layer as compared with decreasing the cavity pressure stepwise as can be seen in Table 2B. Hence higher cavity pressure either in one or stepwise increasing resulted in good quality as compared to lower or stepwise decreasing one. Also maximum thinning of the middle layer occurred when stepwise pressure was decreased which was discouraging.

Our optimized part formed at stepwise increasing the VCP and in this case, maximum forming depth without any wrinkling, delamination or fracture was obtained instead of keeping the pressure constant or lowering stepwise. Hence more forming depth overall resulted in more thinning of three layers as compared to others. Al lower sheet got maximum thinning of $14.96 \%$ while upper aluminum sheet $14.15 \%$ that was less than lower aluminum layer. The middle layer i.e. glass prepreg became thin about $5.66 \%$ which was reasonable. 
Figure 10 given below shows the thinning rate distribution of three layers up to the center of the optimized GLARE cup part separately and combined for whole the laminate as well. Here similarity of the three curves shows that the behavior of the full GLARE laminate was in the same manner and also shows about the good quality of the part, that there was no wrinkling, delamination, or any kind of fracture at this blank holder force, blank holder gap and VCP with encouraging forming depth. At the flange region due to blank holding force, different stresses like radial tensile and compressive stresses occurred and compressive deformation resulted in increasing the thickness of the laminate, as can be seen in the form of negative thinning rate in figure $10(\mathrm{a}, \mathrm{b}, \mathrm{c})$. Whereas, maximum thinning occurred in the punch radius region because of the acting of tensile stresses and bending deformation simultaneously. Also at the center of the punch region thickness was more than its radius area because of increasing the cavity pressure stepwise, hence the maximum pressure of $8 \mathrm{MPa}$ in the last step created maximum friction between punch and laminate.

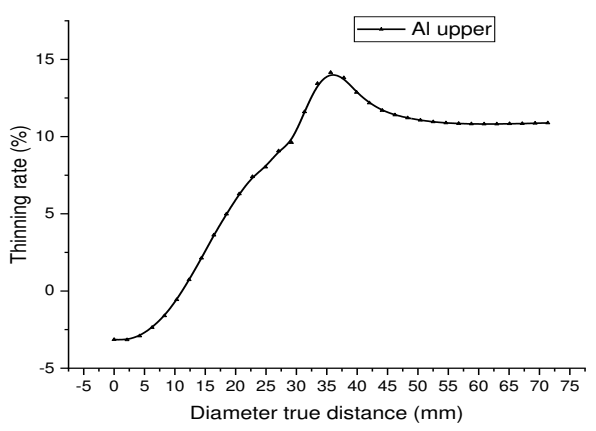

la

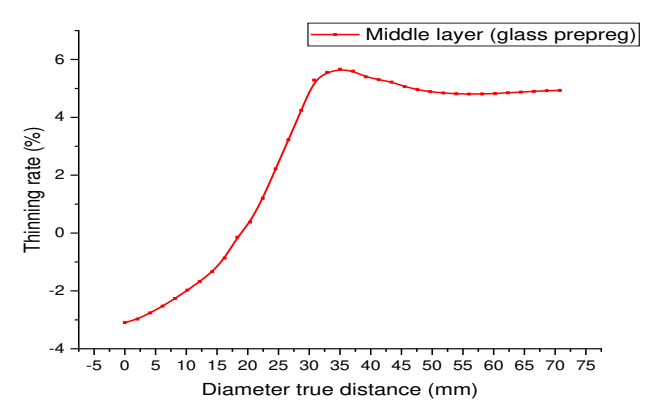

(c)

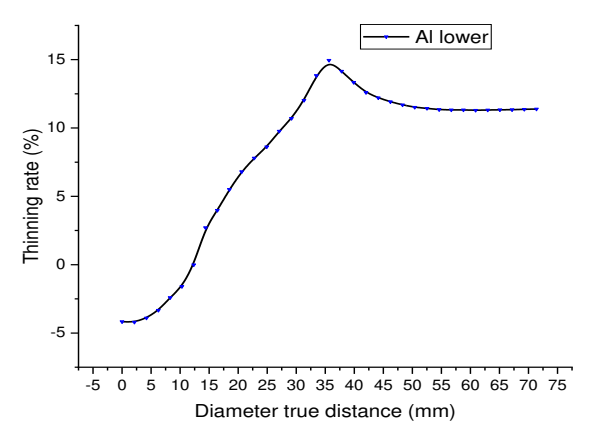

(b

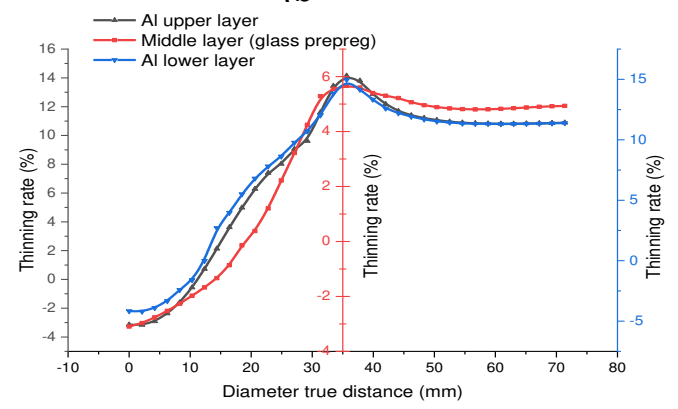

(d

Figure 10: Wall thinning rate (\%) distribution of the part at stepwise increasing VCP up to center of the cup part for specimen B1 (a) Al upper layer (b) middle layer (c) Al lower layer (d) full laminate. 


\section{Conclusion}

The influence of VCP w.r.t punch strokes has been investigated in the forming of the GLARE cup parts by using the HMDD of the 2/1 GLARE laminate.

- In hydroforming, cavity pressure has very much influence on the formability of the part. Cavity pressure more or less than the optimal value results in lower forming depth as well as bad quality. In case of cavity pressure less than the optimal value, wrinkling starts earlier which finally results in the rupture of the parts, and higher cavity pressure results in an early fracture. So, $\mathrm{VCP}$ was used in this study to address the issue.

- It was applied in three different steps w.r.t punch strokes of 0-13, 13-21, and 21-29 mm. At the starting of 1st step which was the first punch stroke when we applied the lowest value of $2 \mathrm{MPa}$, then increased step by step to 5 and $8 \mathrm{MPa}$ respectively, we got the maximum forming depth of the part as well as good quality. Whereas, when cavity pressure was decreased at different steps the results were not encouraging.

- Stepwise decreasing the VCP resulted in sidewall wrinkling while stepwise increasing the VCP more than optimal value resulted in an early fracture.

- Also, lower or stepwise decreasing the VCP resulted in more thinning of the middle layer as compared to higher or stepwise increasing the VCP.

- Finite element analysis had been done by using Abaqus CAE and it was in close agreement with the experimental results.

- Results showed that a maximum forming depth of $29.00 \mathrm{~mm}$, as well as good quality of the parts, was obtained when stepwise increasing the VCP was applied instead of constant or decreasing the cavity pressure.

\section{Declarations}

Consent to participate (All the authors agreed to participate in this research study supported by National Natural Science Foundation of China)

Consent to publish (The authors hereby grant consent to International Journal of Advance Manufacturing Technology for rights to publish this review article)

Competing interest. The authors declare that they have no known competing financial interests or personal relationships that could have appeared to influence the work reported in this paper.

Funding. This research work is supported by the National Natural Science Foundation of China [No. 51675029] and the Science and Technology Project of Sichuan province (2019YFSY0034).

Data Availability Statement. All data generated or analyzed during this study are included in this article. 


\section{$\underline{\text { References }}$}

[1] G. Reyes and H. Kang, "Mechanical behavior of lightweight thermoplastic fiber-metal laminates," J. Mater. Process. Technol., vol. 186, no. 1-3, pp. 284-290, May 2007, doi: 10.1016/j.jmatprotec.2006.12.050.

[2] L. B. Vogelesang and A. Vlot, "Development of fibre metal laminates for advanced aerospace structures," $J$. Mater. Process. Technol., vol. 103, no. 1, pp. 1-5, Jun. 2000, doi: 10.1016/S0924-0136(00)00411-8.

[3] T. Sinmazçelik, E. Avcu, M. Ö. Bora, and O. Çoban, “A review: Fibre metal laminates, background, bonding types and applied test methods," Materials and Design, vol. 32, no. 7. pp. 3671-3685, Aug. 2011, doi: 10.1016/j.matdes.2011.03.011.

[4] A. Asundi and A. Y. N. Choi, "Fiber metal laminates: An advanced material for future aircraft," J. Mater. Process. Technol., vol. 63, no. 1-3, pp. 384-394, Jan. 1997, doi: 10.1016/S0924-0136(96)02652-0.

[5] G. Wu and J. M. Yang, "The mechanical behavior of GLARE laminates for aircraft structures," JOM, vol. 57, no. 1, pp. 72-79, Jan. 2005, doi: 10.1007/s11837-005-0067-4.

[6] “Composites Forming Technologies - 1st Edition.” https://www.elsevier.com/books/composites-formingtechnologies/long/978-1-84569-033-5 (accessed Apr. 03, 2021).

[7] S. H. Zhang, "Developments in hydroforming," J. Mater. Process. Technol., vol. 91, no. 1, pp. 236-244, Jun. 1999, doi: 10.1016/S0924-0136(98)00423-3.

[8] L. Lang, J. Danckert, and K. B. Nielsen, "Investigation into hydrodynamic deep drawing assisted by radial pressure: Part II. Numerical analysis of the drawing mechanism and the process parameters," J. Mater. Process. Technol., vol. 166, no. 1, pp. 150-161, Jul. 2005, doi: 10.1016/j.jmatprotec.2004.08.015.

[9] S. H. Zhang and J. Danckert, "Development of hydro-mechanical deep drawing," J. Mater. Process. Technol., vol. 83, no. 1-3, pp. 14-25, Nov. 1998, doi: 10.1016/S0924-0136(98)00039-9.

[10] A. Gorji, H. Alavi-Hashemi, M. Bakhshi-jooybari, S. Nourouzi, and S. J. Hosseinipour, "Investigation of hydrodynamic deep drawing for conical-cylindrical cups," Int. J. Adv. Manuf. Technol. 2011 569, vol. 56, no. 9, pp. 915-927, Apr. 2011, doi: 10.1007/S00170-011-3263-0.

[11] C. Wang, M. Wan, B. Meng, and L. Xu, "Process window calculation and pressure locus optimization in hydroforming of conical box with double concave cavities," Int. J. Adv. Manuf. Technol., vol. 91, no. 1-4, pp. 847-858, Jul. 2017, doi: 10.1007/s00170-016-9814-7.

[12] M. Khademi, H. Gorji, and M. Bakhshi-Jooybari, "Effects of material and process parameters on wrinkling of conical parts in modified hydroforming process," Int. J. Adv. Manuf. Technol., pp. 1-21, Jun. 2021, doi: 10.1007/s00170-021-07413-8.

[13] W. D. Li, B. Meng, C. Wang, M. Wan, and L. Xu, "Effect of pre-forming and pressure path on deformation 
behavior in multi-pass hydrodynamic deep drawing process," Int. J. Mech. Sci., vol. 121, pp. 171-180, Feb. 2017, doi: 10.1016/J.IJMECSCI.2017.01.010.

[14] “(PDF) An Investigation of Wrinkling and Thinning in Hydroforming Deep Drawing Process with Hemispherical Punch.”

https://www.researchgate.net/publication/262495283_An_Investigation_of_Wrinkling_and_Thinning_in_H ydroforming_Deep_Drawing_Process_with_Hemispherical_Punch (accessed Apr. 18, 2021).

[15] M. Alizad-Kamran, M. Hoseinpour Gollo, A. Hashemi, and S. M. H. Seyedkashi, "Determination of critical pressure in analyzing of rupture instability for hydromechanical deep drawing using advanced yield criterion," Arch. Civ. Mech. Eng., vol. 18, no. 1, pp. 103-113, Jan. 2018, doi:

10.1016/J.ACME.2017.05.008.

[16] R. Zafar, L. Lihui, Z. Rongjing, and W. Shaohua, "Formability analysis of Fiber Metal Laminates using rubber sheet and forming techniques," in Proceedings of 2014 11th International Bhurban Conference on Applied Sciences and Technology, IBCAST 2014, 2014, pp. 44-47, doi: 10.1109/IBCAST.2014.6778118.

[17] R. Zafar, L. Lihui, and Z. Rongjing, "Analysis of hydro-mechanical deep drawing and the effects of cavity pressure on quality of simultaneously formed three-layer Al alloy parts," Int. J. Adv. Manuf. Technol., vol. 80, no. 9-12, pp. 2117-2128, Oct. 2015, doi: 10.1007/s00170-015-7142-y.

[18] R. Zhang, L. Lang, and R. Zafar, "FEM-based strain analysis study for multilayer sheet forming process," Front. Mech. Eng. 2015 104, vol. 10, no. 4, pp. 373-379, Dec. 2015, doi: 10.1007/S11465-015-0371-9.

[19] "Sci-Hub | Investigation into thinning and spring back of multilayer metal forming using hydro-mechanical deep drawing (HMDD) for lightweight parts. The International Journal of Advanced Manufacturing Technology, 82(5-8), 817-826 | 10.1007/s00170-015-7415-5.” https://sci-hub.se/10.1007/s00170-015-74155 (accessed Sep. 20, 2021).

[20] H. Blala, L. Lang, E. Sherkatghanad, and L. Li, "GLARE hydro-mechanical deep drawing analysis based on the forming depth," in Materials Science Forum, 2020, vol. 982 MSF, pp. 75-84, doi:

10.4028/www.scientific.net/MSF.982.75.

[21] L. Li, L. Lang, B. Hamza, and Q. Zhang, "Effect of hydroforming process on the formability of fiber metal laminates using semi-cured preparation," Int. J. Adv. Manuf. Technol., vol. 107, no. 9-10, pp. 3909-3920, Apr. 2020, doi: 10.1007/s00170-020-05281-2.

[22] A. T. Armeki, J. Bazrafshan, and A. Gorji, "Investigation of step pressure path influence on cylindrical cup formation through hydrodynamic deep drawing," Adv. Mater. Process. Technol., vol. 3, no. 2, pp. 174-185, Apr. 2017, doi: 10.1080/2374068X.2016.1160602.

[23] L. Lang, T. Li, D. An, C. Chi, K. B. Nielsen, and J. Danckert, "Investigation into hydromechanical deep drawing of aluminum alloy-Complicated components in aircraft manufacturing," Mater. Sci. Eng. A, vol. 
499, no. 1-2, pp. 320-324, Jan. 2009, doi: 10.1016/j.msea.2007.11.126.

[24] L. Lang, J. Danckert, and K. B. Nielsen, "Study on hydromechanical deep drawing with uniform pressure onto the blank," Int. J. Mach. Tools Manuf., vol. 44, no. 5, pp. 495-502, Apr. 2004, doi:

10.1016/j.ijmachtools.2003.10.028.

[25] K. S. Deep, N. V. Reddy, A. Agrawal, and J. Ramkumar, "A mathematical model for determination of limiting blank holding force and cavity pressure.in hydromechanical deep drawing," in Proceedings of the Institution of Mechanical Engineers, Part B: Journal of Engineering Manufacture, Apr. 2007, vol. 221, no. 2, pp. 155-162, doi: 10.1243/09544054JEM633.

[26] S. Yaghoubi and F. Fereshteh-Saniee, "An investigation on the effects of the process parameters of hydromechanical deep drawing on manufacturing high-quality bimetallic spherical-conical cups,” Int. J. Adv. Manuf. Technol., vol. 110, no. 7-8, pp. 1805-1818, Sep. 2020, doi: 10.1007/s00170-020-05985-5.

[27] A. Jalil, M. Hoseinpour Gollo, M. M. Sheikhi, and S. M. H. Seyedkashi, "Hydrodynamic deep drawing of double layered conical cups," Trans. Nonferrous Met. Soc. China (English Ed., vol. 26, no. 1, pp. 237-247, Jan. 2016, doi: 10.1016/S1003-6326(16)64109-2.

[28] A. Wifi and A. Mosallam, "Some aspects of blank-holder force schemes in deep drawing process Analysis and modelling," 2007.

[29] H. Blala, L. Lang, L. Li, S. Khan, and S. Alexandrov, "Process Control Improvement in Deep Drawing of Hemispherical Cups Made of GLARE Material," MATEC Web Conf., vol. 319, p. 04003, Sep. 2020, doi: 10.1051/matecconf/202031904003.

[30] H. Blala, L. Lang, L. Li, E. Sherkatghanad, and S. Alexandrov, "Investigation on the effect of blank holder gap in the hydroforming of cylindrical cups, made of fiber metal laminate," Int. J. Adv. Manuf. Technol., vol. 108, no. 9-10, pp. 2727-2740, Jun. 2020, doi: 10.1007/s00170-020-05467-8. 